\title{
ORIGINAL
}

\section{DETERMINAÇÃO DO VALOR PROTÉICO DE CÉLULAS ÍNTEGRAS, AUTOLISADO TOTAL E EXTRATO DE LEVEDURA (Saccharomyces sp.)}

\author{
DETERMINATION OF PROTEIN VALUE OF INTEGRAL CELLS, \\ TOTAL AUTOLISATE AND YEAST EXTRACT (Saccharomyces sp.)
}

\author{
Elke Simone Dias VILELA' \\ Valdemiro Carlos SGARBIERI' \\ Izabela Dutra ALVIM'
}

RESUMO

\begin{abstract}
Biomassa de células de levedura, limpa e desamargada, bem como seus derivados autolisado total e extrato de levedura, desidratados em spray dryer foram analisados por ensaio biológico com ratos da linhagem Wistar, em crescimento, para determinação do valor nutritivo da proteína e avaliação do impacto da utilização desses produtos, como única fonte de proteína, nos níveis séricos de triacilgliceróis, colesterol total, ácido úrico e de Lipoproteína de Alta Densidade-colesterol. Células íntegras, autolisado total e extrato de levedura não diferiram estatisticamente $(p \leq 0,05)$ quanto aos índices do quociente de eficiência protéica e quociente de eficiência protéica líquida, significativamente inferiores aos da caseína. A capacidade de produzir crescimento foi maior para a caseína, seguida das células íntegras, do extrato e do autolisado total, em ordem decrescente. A utilização líquida da proteína das dietas confirma os resultados de quociente de eficiência protéica e quociente de eficiência protéica líquida, em que os produtos de levedura não diferiram entre si, mas foram inferiores à caseína. No geral, o valor nutritivo da proteína de levedura variou na faixa de $80-85 \%$ da caseína. Os níveis séricos de ácido úrico se elevaram nos ratos em dietas de levedura, permanecendo porém na faixa considerada de normalidade. A dieta com autolisado total produziu uma redução na concentração sangüínea de triacilgliceróis, o que não ocorreu nas demais dietas. Para colesterol total e Lipoproteína de Alta Densidade-colesterol, todas as dietas de levedura se comportaram semelhantemente, não diferindo entre si e do controle de caseína.
\end{abstract}

Termos de indexação: ratos, proteínas, valor nutritivo, saccharomyces cerevisiae, biomassa, células íntegras, autolisado, extrato.

\begin{abstract}
Clean and debittered yeast cells biomass and its derivatives, total autolisate and extract, after dehydration (spray dryer), were used in a bioassay with wistar rats for determination of protein nutritive value and evaluation of the impact of the yeast products on the blood serum levels of uric acid, triacylglycerols, total cholesterol and High Density Lipoproteins-cholesterol. Integral cells, total autolisate and yeast extract did not differ statistically $(p \leq 0.05)$ regarding Protein Efficiency Ratio and Net Protein Ratio, which were significantly lower than the casein value. The growth promoting capacity was higher for casein, followed by integral cells, yeast extract and total autolisate, in decreasing order of
\end{abstract}

\footnotetext{
${ }^{(1)}$ Instituto de Tecnologia de Alimentos, Centro de Química de Alimentos e Nutrição Aplicada. Av. Brasil, 2880, 13073-001, Campinas, SP, Brasil. Correspondência para/Correspondence to: V.C.SGARBIERI.
} 
magnitude. Net protein utilization values confirmed the Protein Efficiency Ratio and Net Protein Ratio results. Yeast products protein nutritive value was statistically identical but inferior to casein value. On the whole, the nutritive value of the yeast products protein ranked between $80-85 \%$ of the casein value. Uric acid serum concentration increased in the rats fed the diets containing yeast products, but the values remained in the range considered of normality for rats. The diet containing yeast autolisate produced a reduction of the triacylglycerols content, which was not observed in the other diets. For total cholesterol and High Density Lipoproteins-cholesterol all three yeast diets were similar and did not differ from the casein diet.

Index terms: rats, proteins, nutritive value, saccharomyces cerevisiae, biomass, integral cells, autolisate, extract.

\section{INTRODUÇÃO}

A levedura (Saccharomyces sp.) pode ser usada na alimentação humana e animal, sob várias formas e para diversas finalidades (Peixoto, 1996). O uso mais extenso é na panificação, com 120 tonelada/ano, no Brasil. É também largamente usada como agente de fermentação, nas indústrias de fabricação de cerveja, vinhos e álcool. A levedura inativada, pela ação do calor, é usada como fonte de nutrientes em alimentação animal e humana, tanto na forma de levedura íntegra ou de derivados de levedura (Dziezak, 1987a,b; Halász \& Lásztity, 1991).

A levedura é reconhecida mundialmente como excelente fonte de proteínas, vitaminas do complexo B, minerais essenciais e fibra dietética (Reed \& Nagodawithana, 1991). Segundo o Instituto Cubano... (1988), de todas as leveduras, a do gênero Saccharomyces é a de maior valor industrial e comercial, devido ao seu alto teor de lisina. Entretanto, alguns fatores limitam seu uso para o consumo humano, dentre os quais: a presença de parede celular espessa e rígida, resistente à ação de enzimas digestivas (Snyder, 1970; Galvez et al., 1990) e o alto conteúdo de ácidos nucléicos. A ingestão de altas quantidades de ácidos nucléicos leva à acumulação de ácido úrico, que pode cristalizar-se nos tecidos e órgãos, causando a formação de cálculos no tecido urinário e deposição de cálcio nos tecidos moles (Lyutskanov et al., 1990). Por estas razões, é importante o desenvolvimento de métodos de processamento da biomassa, que permitam minimizar os problemas mencionados. Foi demonstrado que isolados protéicos obtidos a partir de células de levedura podem ter melhor qualidade nutricional do que as células íntegras, porque o seu conteúdo de ácidos nucléicos, a presença de componentes ativos indesejáveis e o efeito deletério da parede celular sobre a biodisponibilidade de nutrientes são atenuados (Rosales, 1984).

O uso e a importância do uso de derivados de levedura, como ingredientes flavorizante e complemento nutritivo dos alimentos, têm sido bastante enfatizados na literatura (Yeast..., 1986; Dziezak, 1987a,b; Camerón et al., 1988; Halász \& Lásztity, 1991; Belem \& Lee, 1997; Belem \& Lee, 1998).

O valor nutritivo, particularmente da proteína, de preparados de células íntegras e rompidas mecanicamente e de concentrados protéicos de
Saccharomyces sp., tem sido estudado e publicado (Rumsey et al., 1991; Caballero-Córdoba et al., 1997; Pacheco et al., 1997).

Este trabalho teve como principais objetivos: a) determinar o valor protéico da biomassa (células íntegras) do autolisado total e do extrato da levedura (Saccharomyces sp.), comparativamente à caseína comercial; b) avaliar os efeitos de dietas contendo produtos de levedura nos índices sangüíneos de triacilgliceróis, colesterol total e lipoproteína de alta densidade-colesterol, comparados aos de uma dieta contendo caseína como única fonte de proteína.

\section{MATERIAL E MÉTODOS}

\section{Material}

As amostras de levedura foram gentilmente cedidas pela empresa Produtos Especiais para Alimentos (PRODESA) com sede em Campinas, SP, provenientes de cervejarias. A biomassa, recebida na forma de suspensão de células foi recuperada por centrifugação e submetida a tratamento para o desamargamento e, após desamargamento, parte do lote foi secada em spray dryer, para obtenção de biomassa desidratada, formada de células íntegras (LI). Outra parte foi submetida à autólise em fermentador de 250 L (Newbrunswick - IF 250), para se obter o autolisado total (AT), que após secagem em spray se transformou no autolisado desidratado. Parte do autolisado foi submetido a um fracionamento por centrifugação, originando o extrato de levedura (Ex) e uma fração insolúvel, identificada como parede celular (Pc). Ambas as frações foram obtidas na forma de pó, pela secagem em spray dryer.

Detalhes das operações de limpeza, desamargamento, autólise, fracionamento, secagem e caracterização química da levedura íntegra e dos derivados foram descritos em trabalho anterior (Sgarbieri et al., 1999).

\section{Determinação de aminoácidos}

A determinação de aminoácidos, com exceção do triptofano, foi feita após hidrólise ácida da proteína $\left(\mathrm{HCl} 6 \mathrm{~N}, 110^{\circ} \mathrm{C}, 22 \mathrm{~h}\right.$ ) em aparelho HPLC (Dionex Dx 300), com separação em coluna de troca iônica e reação pós-coluna com ninidrina. 
O triptofano foi determinado após hidrólise enzimática com pronase $\left(24 \mathrm{~h}, 40^{\circ} \mathrm{C}\right)$ seguida de reação colorimétrica com solução de 4-dimetilamino benzaldeído (DAB), em ácido sulfúrico 21,2 N e leitura a 590 nm contra curva padrão de triptofano (Spies, 1967).

\section{Valor nutritivo da proteína}

O valor nutritivo da proteína, dos vários produtos de levedura, foi determinado, comparativamente à caseína, utilizando ratos machos da linhagem Wistar, livres de patógenos (SPF), fornecidos pelo Centro de Animais de Laboratório (CEMIB) da Universidade Estadual de Campinas (UNICAMP). Foram utilizados 40 ratos, com idade entre 21 e 25 dias, no início do ensaio. Após pesagem, os animais foram distribuídos em 5 grupos de 8 ratos cada, sendo cada rato mantido em gaiola individual durante toda a duração do experimento (28 dias), em que receberam água e dieta ad libitum. Durante o experimento, a temperatura do laboratório de ensaio foi mantida em $21 \pm$ $2^{\circ} \mathrm{C}$, com alternância automática de claro-escuro de $12 \mathrm{~h}$.

A composição básica da dieta controle de caseína (Tabela 1), formulada segundo o American Institute of Nutrition (AIN-93G) (Reeves et al., 1993), exceto pela concentração de caseína, que foi mantida ao redor de $10 \%$ $(\mathrm{p} / \mathrm{p})$. Para a execução dos ensaios as seguintes dietas foram preparadas: 1) dieta padrão de caseína (CAS); 2) dieta isenta de proteína, aprotéica (AP); 3) dieta contendo células íntegras de levedura (LI), como única fonte de proteína; 4) dieta contendo autolisado total de levedura (AT), como única fonte de proteína; 5) dieta contendo extrato de levedura (Ex), como única fonte de proteína.

O valor nutritivo da proteína foi estimado através de curvas de crescimento, Quociente de Eficiência Protéica (PER) e Quociente de Eficiência Protéica Líquida (NPR) e de balanço de nitrogênio, que permitiu o cálculo da digestibilidade, valor biológico e índice de utilização líquida da proteína. O NPR (ganho de peso (g) do grupo em dieta experimental + perda de peso (g) do grupo em dieta aprotéica/proteína ingerida (g) pelo grupo em dieta experimental) foi determinado após 21 dias de dieta. $\mathrm{O}$ PER (ganho de peso (g)/proteína ingerida (g)) foi calculado após 28 dias de dieta. Para análise do balanço de nitrogênio (nitrogênio ingerido - nitrogênio excretado nas fezes mais urina) os animais foram mantidos em gaiolas metabólicas durante 8 dias, durante os quais as fezes e a urina foram coletadas para análise de nitrogênio e a ingestão de nitrogênio avaliada, para o cálculo da retenção de nitrogênio no organismo. Essas determinações foram feitas na segunda semana do ensaio. Com os dados do balanço de nitrogênio pode-se calcular: a) digestibilidade da proteína (nitrogênio ingerido/nitrogênio absorvido); b) valor biológico da proteína (nitrogênio retido no organismo/nitrogênio absorvido), c) utilização líquida da proteína (nitrogênio retido no organismo/nitrogênio ingerido). Para o cálculo dos índices verdadeiros de digestibilidade, valor biológico e utilização líquida da proteína, deve-se subtrair do nitrogênio excretado, tanto nas fezes como na urina dos animais dos grupos experimentais, o nitrogênio excretado, respectivamente, nas fezes e urina, do grupo de animais em dieta aprotéica (nitrogênio endógeno).

\section{Determinações no soro sangüíneo}

Como um complemento da avaliação nutricional da proteína, várias determinações no soro sangüíneo dos ratos, foram realizadas:

Triacilgliceróis: foi utilizado o método de Bucolo \& David (1973). Os triacilgliceróis são extraídos com uma mistura de varsol, isopropanol e ácido sulfúrico, havendo separação em fases, com recuperação quantitativa dos triacilgliceróis na fase não-polar (superior), juntamente com as proteínas. Os triacilgliceróis extraídos são saponificados a glicerol e ácidos graxos. O glicerol é oxidado a formaldeído, que forma um complexo, (dihidrolutidina, amarelo) que absorve a $500 \mathrm{~nm}$.

Tabela 1. Composição básica da dieta (AIN-93G) para ratos em crescimento.

\begin{tabular}{lc}
\hline Ingredientes & gramas/kg dieta \\
\hline Amido de milho & 479,839 \\
Caseína (85\% proteína) & 117,647 \\
Amido de milho dextrinizado (90-94\% tetrassacarídeos) & 132,000 \\
Sacarose & 100,000 \\
Óleo de soja & 70,000 \\
Fibra (pó de celulose) & 50,000 \\
Mistura mineral (AIN-93G-MX) & 10,000 \\
L-cistina & 3,000 \\
Bitartarato de Colina (41,1\% Colina) & 2,500 \\
Tert-butil-hidroquinona & 0,014 \\
\hline
\end{tabular}

Fonte: Reeves et al. (1993). 
Colesterol total: o método baseia-se na desesterificação enzimática, pela colesterol esterase, a oxidação do colesterol livre pela colesterol oxidase, com formação de peróxido de hidrogênio $\left(\mathrm{H}_{2} \mathrm{O}_{2}\right) \cdot \mathrm{O} \mathrm{H}_{2} \mathrm{O}_{2}$ reage com o reagente fenol-4-aminoantipirina produzindo, pela ação da peroxidase, o cromóforo antipirilquinonimina, cuja cor vermelha absorve a $500 \mathrm{~nm}$. A determinação se baseia na reação de Lieberman-Buchard e o método foi descrito por Huang et al. (1961). Foi utilizado o Kit Labtest (Labcenter, Campinas, SP).

Lipoproteína de Alta Densidade-colesterol: foi utilizado o método de Friedwald et al. (1972). As lipoproteínas de baixa densidade são separadas do soro sangüíneo por precipitação, mediante complexação com polímeros de alto peso molecular. Após centrifugação, separam-se no sobrenadante as Liproteína de Alta Densidade (HDL) e de muita baixa densidade (VLDL). O colesterol ligado à LDL é determinado pelo sistema enzimático, colesterol oxidase-peroxidase, por reação colorimétrica no sobrenadante, utilizando-se o Kit Labtest (Labcenter, Campinas, SP).

Ácido úrico: o método de dosagem baseia-se na coloração azul, obtida pela ação redutora do ácido úrico sobre o reativo fosfotúngstico, em $\mathrm{pH}$ básico e presença de alantoína e $\mathrm{CO}_{2}$. $\mathrm{O}$ azul de tungstênio formado absorve radiação no comprimento de onda de $700 \mathrm{~nm}$, segundo Berndt \& Davis (1989). Foi utilizado para a dosagem o Kit Labtest (Labcenter, Campinas, SP).

\section{RESULTADOS E DISCUSSÃO}

Pode-se observar que não houve diferença estatística, no consumo de dieta e de proteína, para ratos mantidos em biomassa de células íntegras, extrato de levedura e caseína, que apresentaram valores estatisticamente superiores aos encontrados para o autolisado total. Quanto ao ganho de peso médio dos ratos, verifica-se que a dieta de caseína promoveu o maior ganho de peso e a de autolisado o menor $(p \leq 0,05)$, enquanto que a levedura íntegra e o extrato produziram ganhos intermediários, iguais entre si, mas que diferiu estatisticamente, tanto da caseína como do autolisado. Quanto aos valores de PER e de NPR, levedura íntegra, autolisado total e extrato, não diferiram entre si, estatisticamente, sendo porém inferiores $(p \leq 0,05)$ aos índices fornecidos pela caseína (Tabela 2).

O menor ganho de peso do grupo mantido em dieta com autolisado total parece estar diretamente relacionado com a menor ingestão de dieta e de proteína por esse grupo e não à eficiência da proteína em promover crescimento, como sugerem os índices PER e NPR (Tabela 2).

Na Figura 1 são apresentadas as curvas de variação de peso, para os grupos de ratos mantidos nas várias dietas. Embora não tenha havido diferença estatística nos valores de PER (Tabela 2), entre as dietas com proteína de levedura, houve um crescimento diferenciado, produzido pela biomassa de células íntegras, o extrato de levedura e o autolisado total. Dentre as dietas de levedura, as LI provocaram o maior crescimento e o AT o menor, obtendo-se valores intermediários para o extrato. Essas diferenças podem ser atribuídas a diferenças na ingestão de dieta e de proteína (Tabela 2), uma vez que o Quociente de Eficiência Protéica não variou entre as dietas contendo proteína de levedura. As dietas com proteínas de levedura produziram crescimento inferior ao da caseína.

Na Tabela 3 são apresentados os resultados do balanço de nitrogênio (BN), para os grupos de ratos submetidos às várias dietas contendo levedura, comparativamente à dieta de caseína. Verifica-se não ter havido diferença estatística $(p \leq 0,05)$ na ingestão de nitrogênio para as dietas contendo LI e Ex de levedura comparadas com a caseína, tendo os ratos em dieta AT ingerido quantidade inferior de $N(p \leq 0,05)$. A excreção urinária de nitrogênio foi maior no grupo em dieta com extrato de levedura e estatisticamente diferente $(p \leq 0,05)$ das demais dietas, que não diferiram entre si. A excreção fecal de nitrogênio foi estatisticamente mais elevada na dieta com levedura íntegra $(p \leq 0,05)$, foi inferior para a

Tabela 2. Consumo de dietas, ingestão de proteínas e variação de peso em ratos submetidos aos tratamentos, com caseína (padrão), levedura íntegra, autolisado total e extrato de levedura, em 8 ratos por tratamento com duração de 28 dias.

\begin{tabular}{|c|c|c|c|c|c|}
\hline $\begin{array}{c}\text { Tratamento/proteína } \\
\%\end{array}$ & Dieta consumida & $\begin{array}{l}\text { Proteína consumida } \\
\mathrm{g}\end{array}$ & Variação de peso & PER & NPR \\
\hline \multirow[t]{2}{*}{ Caseína/10,54 } & $267,00^{\mathrm{a}}$ & $28,15^{\mathrm{a}}$ & $111,41^{\mathrm{a}}$ & $3,95^{\mathrm{a}}$ & $4,43^{\mathrm{a}}$ \\
\hline & $(10,32)$ & $(1,08)$ & $(9,35)$ & $(0,19)$ & $(0,17)$ \\
\hline \multirow[t]{2}{*}{ Células íntegras de levedura/10,70 } & $264,26^{\mathrm{a}}$ & $28,28^{\mathrm{a}}$ & $89,82^{\mathrm{b}}$ & $3,17^{\mathrm{b}}$ & $3,65^{b}$ \\
\hline & $(16,93)$ & $(1,83)$ & $(8,63)$ & $(0,15)$ & $(0,14)$ \\
\hline \multirow[t]{2}{*}{ Autolisado total de levedura/9,46 } & $219,88^{b}$ & $20,80^{b}$ & $65,27^{\mathrm{c}}$ & $3,14^{\mathrm{b}}$ & $3,80^{\mathrm{b}}$ \\
\hline & $(17,35)$ & $(1,65)$ & $(13,18)$ & $(0,58)$ & $(0,58)$ \\
\hline \multirow[t]{2}{*}{ Extrato de levedura/10,53 } & $244,66^{\mathrm{a}}$ & $25,78^{\mathrm{a}}$ & $80,11^{b}$ & $3,10^{\mathrm{b}}$ & $3,63^{\mathrm{b}}$ \\
\hline & $(28,27)$ & $(2,95)$ & $(11,50)$ & $(0,20)$ & $(0,18)$ \\
\hline
\end{tabular}

Nota: Valores entre parênteses representam desvios-padrão das médias, letras diferentes (colunas) indicam diferença estatística ( $\mathrm{p} \leq 0,05)$ entre os tratamentos 
dieta de caseína e a dieta contendo extrato de levedura, que não diferiram entre si $(p \leq 0,05)$. $O$ autolisado teve um valor intermediário, entre $\mathrm{LI}$ e as outras duas dietas de levedura. Quanto à quantidade de nitrogênio retida no organismo, verifica-se que a menor retenção de nitrogênio foi para a dieta contendo autolisado total de levedura como fonte de proteína. As demais dietas, caseína, levedura íntegra e extrato de levedura, proporcionaram, estatisticamente, a mesma retenção de nitrogênio, superior à do autolisado.

A digestibilidade verdadeira da proteína foi significativamente maior e idêntica para a caseína e para o extrato de levedura. Os valores para leveduras íntegras e autolisado total não diferiram estatisticamente $(p \leq 0,05)$ e foram inferiores à caseína e ao extrato de levedura. O valor biológico verdadeiro não diferiu estatisticamente para caseína, células íntegras e autolisado de levedura, e foi estatisticamente superior ao valor encontrado para o extrato. Quanto o índice de utilização líquida da proteína (NPUv\%), as três fontes protéicas de levedura não diferiram entre si, sendo inferior ao da caseína (Tabela 4).

A interpretação dos resultados da avaliação nutricional de proteínas pode ser facilitada, à luz do perfil de aminoácidos essenciais (Tabela 5). Como se pode inferir da Tabela 5, o autolisado total foi a única preparação cuja proteína apresentou ligeira deficiência em relação ao padrão de referência oferecido pela Food... (1989). É importante notar que essa deficiência relativa, apresentada pela proteína do autolisado total, pode explicar, em grande parte, a inferioridade observada para o autolisado em relação à retenção de nitrogênio $(\mathrm{BN})$ e ao crescimento dos ratos (Figura 1).

Tabela 3. Nitrogênio ingerido com as dietas, nitrogênio excretado na urina, nitrogênio excretado nas fezes e nitrogênio retido nas dietas de caseína, células íntegras de levedura, autolisado total de levedura e extrato de levedura. Balanço de 8 dias.

\begin{tabular}{|c|c|c|c|c|}
\hline $\begin{array}{l}\text { Tratamentos } \\
\text { (8 ratos) }\end{array}$ & $\mathrm{NI}$ & NU & NF & $\mathrm{BN}$ \\
\hline Caseína $(10,54 \%)$ & $1620 \pm 61^{a}$ & $143 \pm 17^{b}$ & $93 \pm 20^{\mathrm{c}}$ & $1388 \pm 70^{\mathrm{a}}$ \\
\hline Células íntegras de levedura (10,7\% de proteína) & $1798 \pm 139^{\mathrm{a}}$ & $190 \pm 30^{b}$ & $314 \pm 40^{\mathrm{a}}$ & $1390 \pm 160^{a}$ \\
\hline Autolisado total de levedura (9,46\% de proteína) & $1296 \pm 161^{b}$ & $136 \pm 56^{\mathrm{b}}$ & $217 \pm 70^{b}$ & $935 \pm 100^{b}$ \\
\hline Extrato de levedura (10,53\% de proteína) & $1633 \pm 250^{\mathrm{a}}$ & $320 \pm 107^{a}$ & $101 \pm 10^{\mathrm{c}}$ & $1234 \pm 200^{\mathrm{a}}$ \\
\hline
\end{tabular}

$(a, b, c)$ Letras diferentes (colunas) indicam diferença estatística $(p \leq 0,05)$ entre tratamentos

$\mathrm{NI}=$ Nitrogênio; $\mathrm{NU}=$ Nitrogênio Urinário; NF = Nitrogênio Fecal; BN = Balanço de Nitrogênio

Tabela 4. Índices de valor protéico, para a caseína, células íntegras de levedura, autolisado total e extrato de levedura

\begin{tabular}{|c|c|c|c|}
\hline $\begin{array}{l}\text { Tratamento } \\
\text { (8 ratos) }\end{array}$ & Dv & $\begin{array}{r}\text { VBv } \\
-\quad \%\end{array}$ & NPUv \\
\hline Caseína & $95,89 \pm 1,46^{a}$ & $90,44 \pm 1,35^{\mathrm{a}}$ & $86,73 \pm 2,16^{2}$ \\
\hline Células integras de levedura & $83,03 \pm 2,21^{b}$ & $86,26 \pm 3,13^{a}$ & $71,65 \pm 3,85^{b}$ \\
\hline Autolisado total de levedura & $86,49 \pm 4,23^{b}$ & $87,65 \pm 4,53^{\mathrm{a}}$ & $75,91 \pm 6,91^{b}$ \\
\hline Extrato de levedura & $95,38 \pm 0,89^{\mathrm{a}}$ & $79,26 \pm 5,26^{b}$ & $75,58 \pm 4,70$ \\
\hline
\end{tabular}

(a,b) Letras diferentes (colunas) indicam diferença estatística $(p \leq 0,05)$ entre tratamentos

DV = Digestibilidade Verdadeira; VBv = Valor Biológico Verdadeiro; NPUv = Utilização Líquida da Proteína Verdadeira.

Tabela 5. Adequação de aminoácidos essenciais das células íntegras de levedura, autolisado total e extrato de levedura, tendo por base o padrão de referência da $\mathrm{FAO} / \mathrm{WHO}$.

\begin{tabular}{|c|c|c|c|c|}
\hline Aminoácidos essenciais (mg/100 mg de proteína) & Padrão FAO/WHO & Células Íntegras & Autolisado Total & Extrato de Levedura \\
\hline Treonina & 3,4 & 6,16 & 5,84 & 5,19 \\
\hline Metionina + cisteína & 2,5 & 2,84 & $2,11^{*}$ & 3,56 \\
\hline Valina & 3,5 & 6,20 & 5,87 & 6,76 \\
\hline Leucina & 6,6 & 8,84 & 7,80 & 8,07 \\
\hline Isoleucina & 2,8 & 5,64 & 4,87 & 5,69 \\
\hline Fenilalanina + Tirosina & 6,3 & 9,98 & 8,53 & 6,91 \\
\hline Lisina & 5,8 & 7,13 & 9,54 & 8,58 \\
\hline Histidina & 1,9 & 2,06 & 3,15 & 3,01 \\
\hline Triptofano & 1,1 & 1,45 & 1,55 & 1,31 \\
\hline
\end{tabular}

(*) Aminoácido limitante (84\% do recomendado) - Food... (1989). 


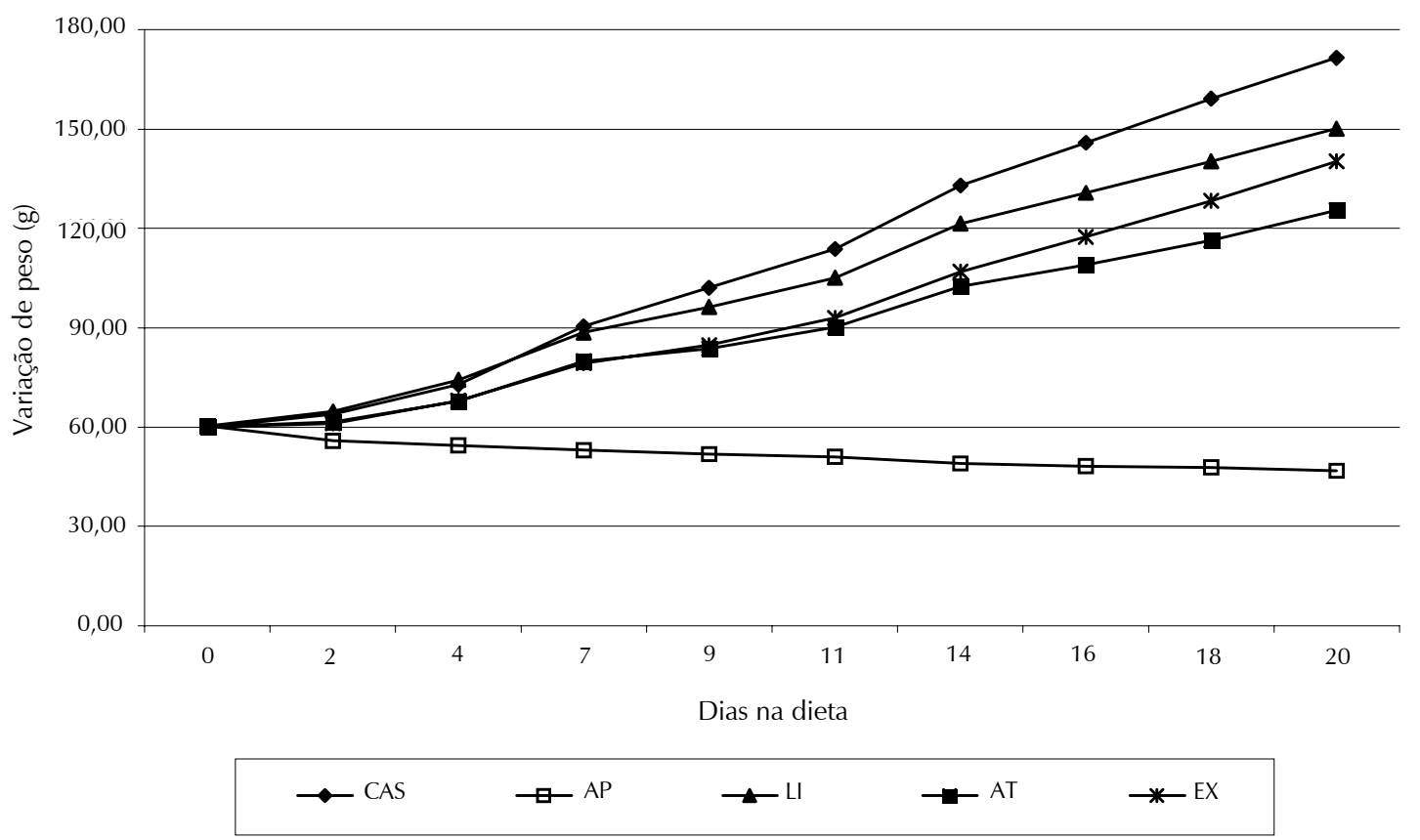

Figura 1. Evolução do peso corporal de ratos submetidos durante 20 dias a dieta contendo como única fonte de proteína: caseína (CAS); células íntegras de levedura (LI); autolisado total de levedura (AT); extrato de levedura (Ex) e dieta aprotéica (AP).

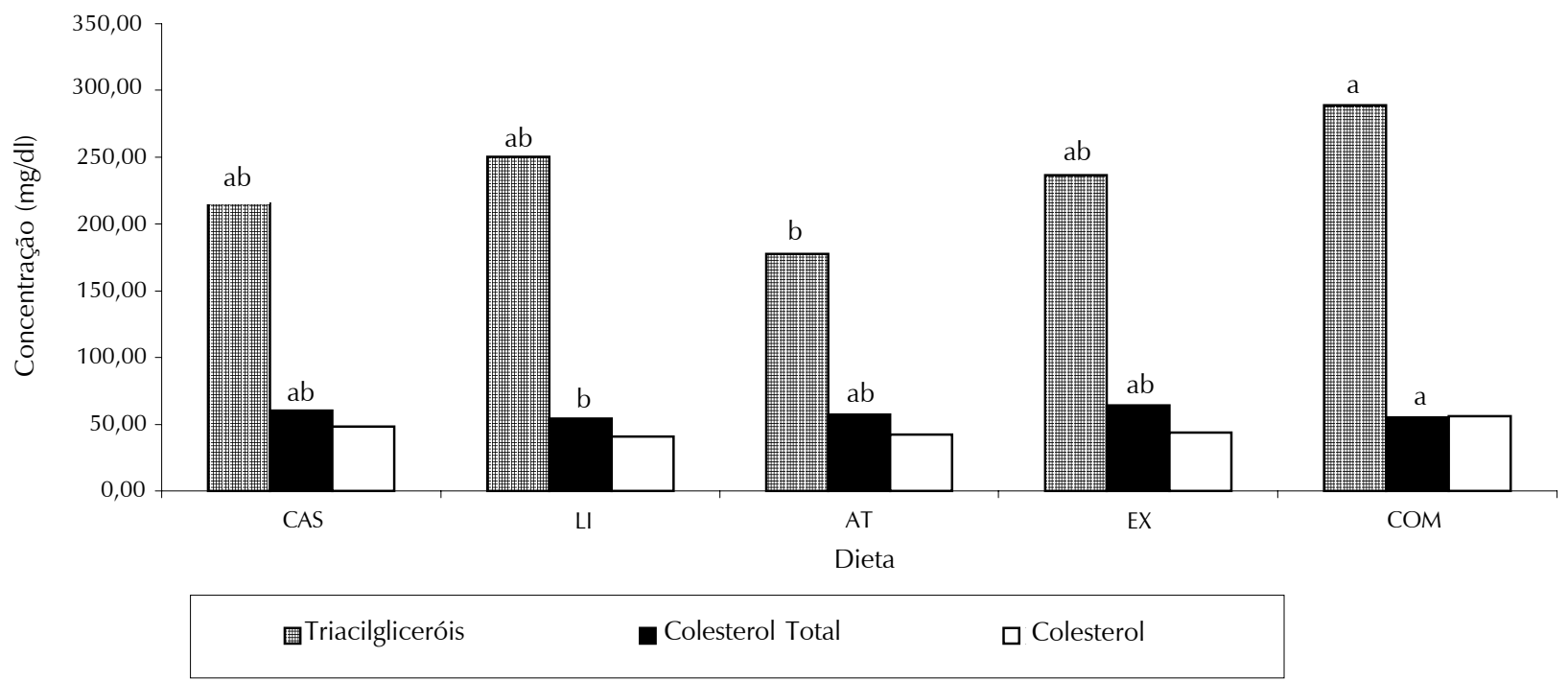

Figura 2. Representação gráfica dos índices séricos de triacilgliceróis, colesterol total e HDL - colesterol em ratos alimentados 28 dias com dietas contendo: caseína (CAS); células íntegras de levedura (LI); autolisado total de levedura (AT) e extrato de levedura (EX) na base de $10 \%$ de proteína e uma dieta comercial (COM).

Nota: Letras diferentes sobre as barras indicam diferença estatística $(p=0,05)$ entre os tratamentos.

Dados da literatura Calloway (1974) e Smith \& Palmer (1976) indicam deficiências em aminoácidos sulfurados para Saccharomyces cerevisiae e Torula. Resultados de valor biológico, reportados, estão na faixa de $60-90 \%$. Smith \& Palmer (1976) reportaram valor de 47,79 e $50 \%$ para NPU, digestibilidade e valor biológico, respectivamente: valores que foram elevados para 58, 93 e 67\%, respectivamente, pela adição de $1,8 \%$ L-metionina mais $0,05 \%$ histidina.

Valores encontrados em nosso laboratório (Caballero-Córdoba et al., 1997; Pacheco et al., 1997; Caballero-Córdoba \& Sgarbieri, 2000), para os índices indicativos de valor nutritivo da proteína de levedura, em suas várias formas, como células íntegras, autolisado, 
extrato e concentrados protéicos, têm sido superiores aos reportados na literatura. Essa relativa melhoria no valor nutritivo da proteína poderia ser explicado pelo preparo mais cuidadoso da biomassa e ajustes do processamento para obtenção dos vários derivados da levedura.

De um modo geral, as várias preparações de levedura obtidas em nosso laboratório têm apresentado valor protéico na faixa 75-90\% da caseína, dependendo do índice de avaliação considerado.

A concentração de ácido úrico, no soro sangüíneo dos ratos, se elevou de 1,74 mg/dl nos ratos em dieta de caseína, para valores na faixa de 2,1 (Ex) a 2,4 (AT). Esses resultados estão dentro da faixa de valores mencionados na literatura $(1,2-7,5 \mathrm{mg} / \mathrm{dl})$ para ratos normais (Mitruka \& Rawnsley, 1981). Considerando o valor $1,74 \mathrm{mg} / \mathrm{dl}$ encontrado para caseína, os valores de 2,1 a 2,4 não representam elevação muito grande e, portanto, não se deve esperar que possam representar problema de toxicidade para os ratos.

Observa-se uma pequena redução dos níveis de triacilgliceróis no soro dos ratos em dieta de caseína, de células íntegras e de extrato de levedura, em relação à dieta comercial, embora sem diferença estatística significativa $(p \leq 0,05)$. Por outro lado, houve diminuição estatística significativa ( $p \leq 0,05)$ dos triacilgliceróis, no soro dos ratos em dieta contendo autolisado total de levedura. Os níveis de colesterol total e de HDL-colesterol permaneceram praticamente iguais na caseína e nas dietas contendo proteína de levedura (Figura 2).

\section{CONCLUSÃO}

Com base nos dados apresentados neste trabalho, pode-se concluir: a) a composição em aminoácidos essenciais da proteína, nos produtos de levedura estudados, não apresentou nenhuma deficiência em relação ao padrão de referência da Food and Agriculture Organization/World Health Organization, exceto pelo autolisado total que apresentou escore químico de $84 \%$ do padrão, com base nos aminoácidos sulfurados totais, metionina mais cisteína; b) quanto à capacidade de produzir crescimento, em ratos recém-desmamados, as células íntegras foram ligeiramente superiores ao extrato e este superior ao autolisado, e as três fontes protéicas foram inferiores à caseína, embora, do ponto de vista da eficiência protéica (PER e NPR), os produtos de levedura não diferiram entre $\mathrm{si}$; c) a presença de parede celular (células íntegras, autolisado) diminuiu significativamente a digestibilidade, embora não tenha afetado a utilização líquida da proteína; d) dependendo do índice de avaliação adotado, o valor nutritivo da proteína de levedura, nos vários produtos, representou
80-85\% do valor da caseína; e) os níveis de ácido úrico se elevaram no soro sangüíneo dos ratos em dieta de levedura, permanecendo, porém, dentro da faixa considerada normal; f) a dieta com autolisado total de levedura provocou uma diminuição significativa de triacilgliceróis no soro sangüíneo dos ratos; g) conclui-se que os produtos de levedura contêm proteína de boa qualidade nutricional, podendo ser recomendados como parte da dieta humana, em suas várias formas.

\section{AGRADECIMENTOS}

Os autores agradecem ao auxílio financeiro concedido pela FAPESP - Fundação de Apoio à Pesquisa do Estado de São Paulo, para a realização desta pesquisa; à empresa PRODESA - Produtos Especiais para Alimentos por ter fornecido, gentilmente, a levedura para estudo.

\section{REFERÊNCIAS BIBLIOGRÁFICAS}

BELEM, M.A.F., LEE, B.H. Production of RNA derivatives by Kluyveromyces fragilis grown on whey. Food Science and Technology International, London, v.3, n.6, p.437-444, 1997.

BELEM, M.A.F., LEE, B.H. Production of bioingredients from Kluyveromyces marxianus grown on whey: an alternative. Critical Reviews in Food Science and Nutrition, Cleveland, v.38, n.7, p.565-598, 1998.

BERNDT, W.O., DAVIS, M.E. Renal methods for toxicology. In: HAYES, A.W. (Ed.). Principles and methods for toxicology. 2.ed. New York: Raven Press, 1989. 929p.

BUCOLO, G., DAVID, E. Quantitative determination of serum triglycerides by the use of enzymes. Clinical Chemistry, Baltimore, v.19, n.5, p.476-482, 1973.

CABALLERO-CÓRDOBA, G.M., PACHECO, M.T.B., SGARBIERI, V.C. Composição química de biomassa de levedura integral (Saccharomyces sp.) e determinação do valor nutritivo da proteína, em células íntegras ou rompidas mecanicamente. Ciência e Tecnologia de Alimentos, Campinas, v.17, n.2, p.102-106, 1997.

CABALLERO-CÓRDOBA, G.M., SGARBIERI, V.C. Nutritional and toxicological evaluation of yeast (Saccharomyces cerevisiae) biomass and a yeast protein concentrate. Journal of the Science of Food and Agriculture, London, v.80, p.341-351, 2000.

CALLOWAY, D.H. The place of single cell protein (SCP) in man's diet. In: DAVIS, P. (Ed.). Single cell protein. New York : Academic Press, 1974. p.129.

CAMERÓN, D.R., COOPER, D.G., NEUfELD, R.J. The mannoprotein of Saccharomyces cerevisiae is an effective bioemulsifier. Applied and Environmental Microbiology, Washington DC, v.54, n.6, p.1420-1425, 1988.

DZIEZAK, J. Yeasts and yeast derivatives: definitions, characteristics, and processing. Food Technology, Chicago, v.41, n.2, p.104-121, 1987 a.

DZIEZAK, J. Yeasts and yeast derivatives: applications. Food Technology, Chicago, v.41, n.2, p.122-125, 1987b. 
FOOD AND AGRICULTURE ORGANIZATION. Protein quality evaluation. Rome, 1989. 27p. (Report of the Joint FAO/WHO Expert Consultation, Food and Nutrition Paper, n.51).

FRIEDWALD, W.T., LEVY, R.I., FREDRICKSON, D.S. Estimation of concentration of low-density lipoprotein cholesterol in plasma, without use of preparative ultracentrifugation. Clinical Chemistry, Baltimore, v.18, n.6, p.499-502, 1972.

GALVEZ, A., RAMÍREZ, M.J., GARCIA-GARIBAY, M. Chemical composition of a mixture of single cell protein obtained from Kluyveromyces fragilis and whey proteins. Archivos Latinoamericanos de Nutrición, Guatemala, v.40, n.2, p.252262, 1990.

HALÁSZ, A., LÁSZTITY, R. Use of yeast biomass in food production. Boca Raton : CRC Press, 1991. 312p.

HUANG, T.C., CHEN, C.P., WEFLR, V., RATTERY, A.A. A stable reagent for the Lieberman-Buchard reaction. Analytical Chemistry, Washington DC, v.33, n.10, p.1405-1407, 1961.

INSTITUTO CUBANO DE INVESTIGACIONES DE LOS DERIVADOS DE LA CAÑA DE AZÚCAR. Manual de los derivados de la caña de azúcar. Mexico : GEPLACEA/PNUD, 1988. 252p.

LYUTSKANOV, N., KOLEVA, L., STATEVA, L., VENKOV, P., HADJIOLOV, A. Protein extracts for nutritional purposes from fragile strains of Saccharomyces cerevisiae: reduction of nucleic acid content and applicability of the protein extracts. Journal of Basic Microbiology, Berlin, v.30, n.7, p.523-528, 1990.

MITRUKA, M.B.; RAWNSLEY, H.M. Clinical, biochemical and hematological reference values in normal experimental animals and normal humans. 2.ed. New York : Masson Publishing, 1981. 314p.

PACHECO, M.T.B., CABALLERO-CÓRDOBA, G.M., SGARBIERI, V.C. Composition and nutritive value of yeast biomass and yeast protein concentrates. Journal of Nutritional Sciences and Vitaminology, Tokyo, v.43, n.6, p.601-612, 1997.

PEIXOTO, N. Processamentos de produtos de biomassa de levedura para alimentação humana: potencial, mercado interno e externo. In: WORKSHOP SOBRE PRODUÇÃO DE
BIOMASSA DE LEVEDURA: UTILIZAÇÃO EM ALIMENTAÇÃO HUMANA E ANIMAL, 1996, Campinas. Anais... Campinas : ITAL, 1996. p.90-98.

REED, G., NAGODAWITHANA, T.W. Yeast technology. 2.ed., New York : Van Nostrand Reinhold, 1991. 378p.

REEVES, P.G., NIELSEN, F.H., FAHEY Jr., G.C. AIN-93 purified diets for laboratory rodents: final report of the American Institute of Nutrition ad hoc Committee on the reformulation of the AIN-76a Rodent Diet. Journal of Nutrition, Bethesda, v.123, n.2, p.467-472, 1993.

ROSALES, F.H. Yeast as protein source for human nutrition. A review. Acta Microbiology of the Academy of Science of Hungary, Budapest, v.31, n.3, p.159-172, 1984.

RUMSEY, G.L., HUGHES, S.G., SMITH, R.R., KINSELLA, J.E., SHETTY, K.J. Digestibility and energy values of intact, disrupted and extracts from brewer's dried yeast fed to raimbow trout. Animal Feed Science and Technology, Amsterdam, v.33, n.3/4, p.185-193, 1991.

SGARBIERI, V.C., ALVIM, I.D., VILELA, E.S.D., BALDINI, V.L.S., BRAGAGNOLO, N. Produção piloto de derivados de levedura (Saccharomyces sp.) para uso como ingrediente na formulação de alimentos. Brazilian Journal of Food Technology, Campinas, v.2, n.5, p.119-125, 1999.

SMITH, R.H., PALMER, R. A chemical and nutritional evaluation of yeasts and bacteria as dietary protein sources for rats and pigs. Journal of the Science of Food and Agriculture, London, v. 27, n.8, p.763-768, 1976.

SNYDER, H.E. Microbial sources of protein. Advances in Food Research, New York, v.18, p.85-91, 1970.

SPIES, J.R. Determination of tryptophan in proteins. Analytical Chemistry, Washington DC, v.39, n.10, p.1412-1415, 1967.

YEAST protein enhances flavour and nutrition. Food Processing, Chicago, p.13-14, Oct. 1986.

Recebido para publicação em 14 de maio e aceito em 11 de novembro de 1999. 